Neuroprogression in Psychiatric Disorders 


\section{Modern Trends in Pharmacopsychiatry}

Vol. 31

Series Editor

B.E. Leonard Galway 


\section{Neuroprogression in Psychiatric Disorders}

Volume Editors

Angelos Halaris Chicago, IL

Brian E. Leonard Galway

31 figures, 8 in color, and 3 tables, 2017 


\section{Modern Trends in Pharmacopsychiatry \\ (Formerly published as 'Modern Problems in Pharmacopsychiatry')}

\author{
Angelos Halaris \\ Department of Psychiatry and Behavioral Neuroscience \\ Loyola University Stritch School of Medicine \\ and \\ Loyola University Medical Center \\ Chicago, IL (USA)
}

\author{
Prof. Brian E. Leonard \\ Department of Pharmacology \\ Centre for Pain Research and \\ Galway Neuroscience Centre \\ National University of Ireland \\ Galway (Ireland)
}

Library of Congress Cataloging-in-Publication Data

Names: Halaris, Angelos, editor.| Leonard, B. E., editor.

Title: Neuroprogression in psychiatric disorders / volume editors, Angelos

Halaris, Brian E. Leonard.

Other titles: Modern trends in pharmacopsychiatry ; v. 31. 1662-2685

Description: Basel ; New York : Karger, 2017.| Series: Modern trends in pharmacopsychiatry, ISSN 1662-2685; vol. 31 | Includes bibliographical references and index.

Identifiers: LCCN 2017025712| ISBN 9783318060508 (hard cover : alk. paper) |

ISBN 9783318060515 (electronic version)

Subjects: | MESH: Mental Disorders--physiopathology | Disease Progression

Classification: LCC RC454.4 | NLM WM 140 | DDC 616.89--dc23 LC record available at

https://lccn.loc.gov/2017025712

Bibliographic Indices. This publication is listed in bibliographic services, including Current Contents ${ }^{\circledR}$ and PubMed/MEDLINE.

Disclaimer. The statements, opinions and data contained in this publication are solely those of the individual authors and contributors and not of the publisher and the editor(s). The appearance of advertisements in the book is not a warranty, endorsement, or approval of the products or services advertised or of their effectiveness, quality or safety. The publisher and the editor(s) disclaim responsibility for any injury to persons or property resulting from any ideas, methods, instructions or products referred to in the content or advertisements.

Drug Dosage. The authors and the publisher have exerted every effort to ensure that drug selection and dosage set forth in this text are in accord with current recommendations and practice at the time of publication. However, in view of ongoing research, changes in government regulations, and the constant flow of information relating to drug therapy and drug reactions, the reader is urged to check the package insert for each drug for any change in indications and dosage and for added warnings and precautions. This is particularly important when the recommended agent is a new and/or infrequently employed drug.

All rights reserved. No part of this publication may be translated into other languages, reproduced or utilized in any form or by any means electronic or mechanical, including photocopying, recording, microcopying, or by any information storage and retrieval system, without permission in writing from the publisher.

(c) Copyright 2017 by S. Karger AG, P.O. Box, CH-4009 Basel (Switzerland)

www.karger.com

Printed on acid-free and non-aging paper (ISO 9706)

ISSN 1662-2685

e-ISSN 1662-4505

ISBN 978-3-318-06050-8

e-ISBN 978-3-318-06051-5 


\section{Contents}

VII Preface

Halaris, A. (Chicago, IL); Leonard, B.E. (Galway)

1 Neuroprogression in Schizophrenia and Psychotic Disorders: The Possible Role of Inflammation

Müller, N. (Munich)

10 The Link between Refractoriness and Neuroprogression in Treatment-Resistant Bipolar Disorder

Bauer, I.E.; Soares, J.C.; Selek, S.; Meyer, T.D. (Houston, TX)

27 Neuroprogression and Immune Activation in Major Depressive Disorder Meyer, J.H. (Toronto, ON)

37 Inflammation Effects on Glutamate as a Pathway to Neuroprogression in Mood Disorders Haroon, E.; Miller, A.H. (Atlanta, GA)

56 Major Depression as a Neuroprogressive Prelude to Dementia: What Is the Evidence? Leonard, B.E. (Galway)

67 Innate Immune Memory: Implications for Microglial Function and Neuroprogression Salam, A.P.; Pariante, C.M.; Zunszain, P. (London)

79 Inflammatory and Innate Immune Markers of Neuroprogression in Depressed and Teenage Suicide Brain

Pandey, G.N. (Chicago, IL)

96 Towards an Integrated View of Early Molecular Changes Underlying Vulnerability to Social Stress in Psychosis

Barron, H.; Hafizi, S.; Mizrahi, R. (Toronto, ON)

107 Neurodegeneration, Neuroregeneration, and Neuroprotection in Psychiatric Disorders Tang, S.W. (Hong Kong/Irvine, CA); Helmeste, D.M. (Hong Kong); Leonard, B.E. (Hong Kong/Galway)

124 The Contribution of Adult Hippocampal Neurogenesis to the Progression of Psychiatric Disorders

Kohman, R.A. (Wilmington, NC); Rhodes, J.S. (Urbana, IL) 
152 The Brain-Gut Axis Contributes to Neuroprogression in Stress-Related Disorders Rea, K.; Dinan, T.G.; Cryan, J.F. (Cork)

162 Pharmacological and Nonpharmacological Interventions to Arrest Neuroprogression in Psychiatric Disorders

Boufidou, F. (Athens); Halaris, A. (Chicago, IL/Maywod, IL)

177 Author Index

178 Subject Index 


\section{Preface}

Psychiatric and neurological disorders are chronic illnesses characterized by recurrence and relapses and progressively increasing dysfunction. The term "neuroprogression" refers to the temporal clinical progression in most of these disease entities. One of the main factors associated with neuroprogression and, consequently, with disease prognosis, is the frequency of mood episodes, as, for instance, occurs in bipolar and unipolar affective illnesses, but also in psychotic and cognitive disorders including schizophrenic and schizoaffective conditions and the dementias. It is believed the higher the frequency of mood or psychotic episodes, the faster will be the course of neuroprogressive changes rendering the prognosis unfavorable. The biological mechanisms underlying neuroprogression are not fully elucidated and likely involve complex interactions among multiple genes, environmental factors, and epigenetic changes ultimately resulting in impairment in several physiological systems. Neurobiological mechanisms and possibly associated neuroanatomical brain changes in patients with multiple mood episodes appear to include a proinflammatory state, increased oxidative stress, and a deficit in neuroprotection and neuroplasticity. Immune system dysfunction and brain-immune interactions have already been identified in numerous studies as crucial contributory factors to neurogression. Acute mood episodes have been associated with significant systemic toxicity, cognitive and functional impairment, and biolog- ical changes. These effects are cumulative, being much more prominent after multiple episodes. The neuroprogressive nature of most psychiatric and neuropsychiatric disorders thus induces allostatic states with a steadily increasing allostatic load.

Neuroprogression has important clinical implications, both in terms of early detection and prevention, as well as in the selection of appropriate treatment strategies, given that early and late stages of the specific disorder may present different biological features and substrates. Therefore, it is important to conduct longitudinal studies in evaluating the effects of illness progression on neuronal structures and psychoneuroimmune functions. We believe these findings will soon begin to have significant clinical implications by establishing reliable tests for monitoring the impact of treatments, and by supporting more aggressive and earlier therapeutic and preventive interventions to minimize affective and cognitive symptomatology and clinical deterioration. The possibility of identifying neuroanatomical, psychoneuroimmunological, and neurotransmitter abnormalities along with the detection of genetic and epigenetic vulnerability will ultimately unravel some of the potential pathophysiological mechanisms involved in illness progression. Diagnostic accuracy, precise treatment choices, remission, and relapse prevention, along with early detection of illness vulnerability, are the gold standards we need to be aiming for as clinicians and scientists. 
Based on their particular area of expertise and endeavor, the contributors to this volume critically review recent advances in neuroprogression research and its relevance to the impact of chronic psychiatric and neurological disorders on brain structure and function. In addition to the longterm outcome of such disorders, the epigenetic consequences of early childhood abuse on subsequent adverse changes in brain function, which may prelude major psychiatric disorders, have also been considered. The importance of recent postmortem studies and the status of biomarkers provide much of the evidence in support of neuroprogression in psychiatric and neurological disorders.

Angelos Halaris

Brian E. Leonard 